\title{
Investigation of Formation, Recognition, Stabilization, and Conversion of Dimeric G- Quadruplexes of HIV-1 Integrase Inhibitors by Electrospray Ionization Mass Spectrometry
}

\author{
Huihui Li, Gu Yuan, and Daming Du \\ Beijing National Laboratory for Molecular Sciences, Key Laboratory of Bioorganic Chemistry and Molecular \\ Engineering of the Ministry of Education, Department of Chemical Biology, College of Chemistry and \\ Molecular Engineering, Peking University, Beijing, China
}

The dimeric G-quadruplex structures of d(GGGTGGGTGGGTGGGT) (S1) and d(GTGGTGGGTGGGTGGGT) (S2), the potent nanomolar HIV-1 integrase inhibitors, were detected by electrospray ionization mass spectrometry (ESI-MS) for the first time. The formation and conversion of the dimers were induced by $\mathrm{NH}_{4}^{+}$, DNA concentration, $\mathrm{pH}$, and the binding molecules. We directly observed the specific binding of a perylene derivative (Tel03) and $\operatorname{Im} \operatorname{Im} \operatorname{Im} \beta \mathrm{Dp}$ in one system consisting of the intramolecular and the dimeric G-quadruplexes of the HIV-1 integrase inhibitor, which suggested that Tel03 could shift the equilibrium to the dimeric G-quadruplex formation, while $\operatorname{Im} \operatorname{Im} \operatorname{Im} \beta \mathrm{Dp}$ induces preferentially a structural change from the dimer to the intramolecular G-quadruplex. The results of this study indicated that Tel03 and $\operatorname{ImImIm} \beta D p$ favor the stabilization of the dimeric G-quadruplex structures. (J Am Soc Mass Spectrom 2008, 19, 550-559) (C 2008 American Society for Mass Spectrometry

$\mathrm{H}$ IV-1 integrase (IN), a retroviral-encoded enzyme, catalyses the integration of proviral DNA into the host cell chromosomes, which is a key process for efficient viral replication. Since HIV-1 IN has a very important role in the infection cycle of the virus [1-6], it is an attractive target for new AIDS chemotherapeutics $[7,8]$.

The G-rich oligonucleotides were demonstrated recently to inhibit HIV-1 IN by forming a G-quadruplex structure in the presence of monovalent cations $\left(\mathrm{M}^{+}\right)$, which consists of four-stranded structures stabilized by G-tetrads (Scheme 1a), [9-14]. One such inhibitor is T30175, a 17-mer oligonucleotide with a natural phosphodiester (PD) backbone. Another version, T30177, has the same sequence as T30175, but contains two single phosphorothioate (PT) internucleoside linkages. T30923 and its homologue with two PT linkages, T30695, are potent integrase inhibitors. It had been shown that these G-quadruplexes can inhibit the activity of HIV-1 integrase with $\mathrm{IC}_{50}$ values in the nanomolar range $[14,15]$.

The inhibitory activities of the G-quadruplexes are related to their properties [11, 12], such as stability and conversion. In this research, the base sequences of single-stranded oligonucleotides are 5'-GGGTGGGT-

Address reprint requests to Professor Gu Yuan, Beijing National Laboratory for Molecular Sciences, Key Laboratory of Bioorganic Chemistry and Molecular Engineering of Ministry of Education, Department of Chemical Biology, College of Chemistry and Molecular Engineering, Peking University, Beijing 100871, China. E-mail: guyuan@pku.edu.cn
GGGTGGGT-3' (S1) and (5'-GTGGTGGGTGGGTGGGT-3' (S2), two inhibitors of potent nanomolar HIV-1 integrase [9-14].

The design of a ligand that stabilizes the folded G-quadruplex structure is extremely important in HIV-1 integrase inhibition strategy. The success of G-quadruplex interactive agents as potential drugs or biological probes depends on their selectivities for Gquadruplex structures. Consequently, drug design has focused on the issues of binding affinity, specificity, and stability of the G-quadruplex. To improve the stability of the G-quadruplex, the binding molecules were synthesized, such as a perylene derivative (Tel03), polyamides (ImImIm $\beta \mathrm{Dp}$ and PyPyPy $\beta \mathrm{Dp}$ ), and macrocyclic phosphoramidates (Dpku-n, $n=13,14$ ) (Scheme $1 b)$, and used to explore their function to stabilizing of the G-quadruplex [16-18].

Here, we report the unusual dimeric G-quadruplexes of the two HIV-1 integrase inhibitors, which were detected by ESI-MS [19-30] for the first time and established some of their properties, in particular their formation, conversion, recognition, and stabilization.

\section{Experimental}

\section{Binding Molecules}

Tel03, ImImIm $\beta$ Dp, and PyPyPy $\beta$ Dp were synthesized in our laboratory [31]. Dpku-n $(n=13,14)$ were synthesized by Professor Daming Du [32]. 


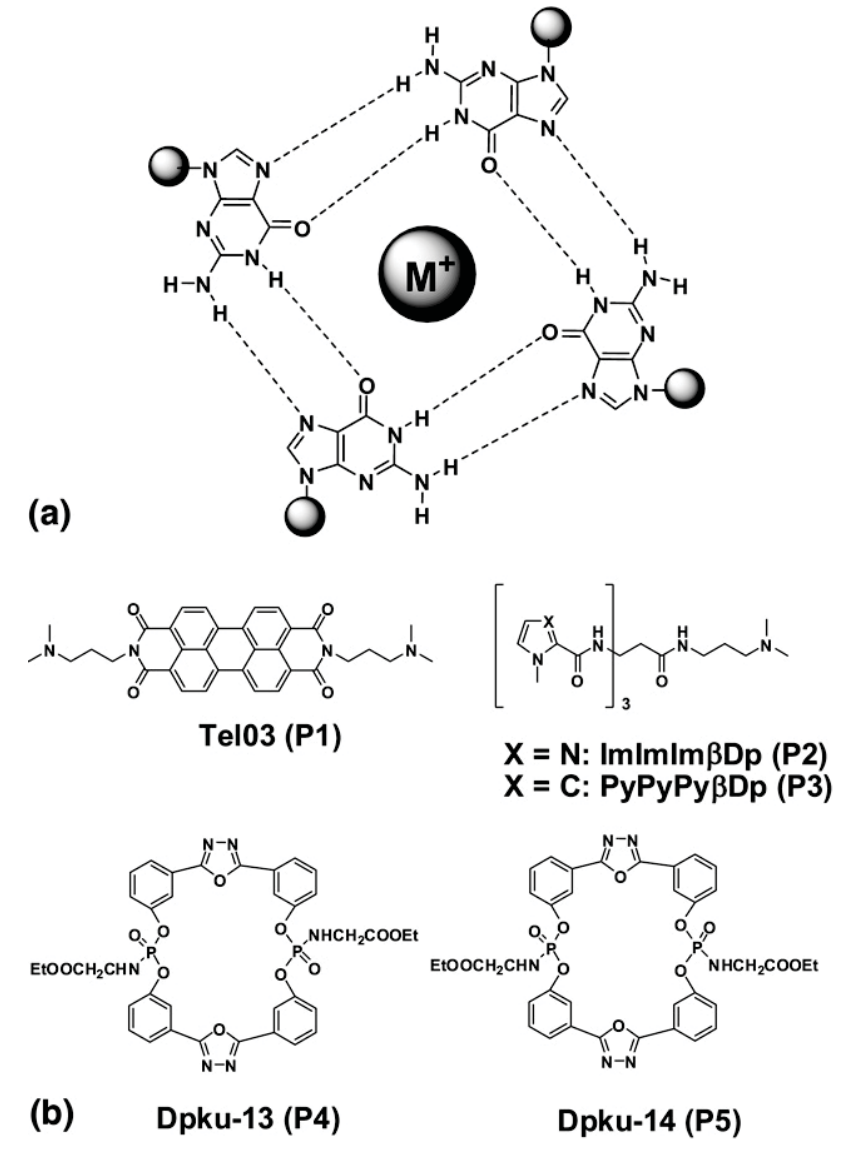

Scheme 1. Schematic of a G-tetrad (a) and binding molecules (b).

\section{Oligonucleotides}

Single-stranded oligonucleotides were purchased from AuGCT, Beijing, China, the abbreviations S1 was used for dGGGTGGGTGGGTGGGT (MW = 5103) and S2 for dGTGGTGGGTGGGTGGGT (MW = 5407), which had been demonstrated to inhibit the activity of HIV-1 IN by forming G-quadruplex structures [9-14]. The oligonucleotides were directly dissolved in deionization water or ammonium acetate solution, the resulting stock solution was $400 \mu \mathrm{M}$ DNA. The DNA solution was diluted with methanol/water $(25: 75$, vol/vol) before the electrospray experiment. Methanol was used to obtain a good spray [33, 34].

\section{Mixing and Binding Assays}

Binding molecules were dissolved at a concentration of $100 \mu \mathrm{M}$ in methanol/water (50:50, vol/vol). A $1.0 \mu \mathrm{L}$ sample of each DNA solution was mixed with 1.0-8.0 $\mu \mathrm{L}$ of binder solution, and then diluted with methanol/ $100 \mathrm{mM}$ ammonium acetate $(25: 75, \mathrm{vol} / \mathrm{vol})$ to $40 \mu \mathrm{L}$ (final concentration was $10 \mu \mathrm{M}$ for each DNA) [33, 34].

\section{Mass Spectrometry}

Normal ESI mass spectra were obtained in the negative-ion mode with a Finnigan LCQ Deca XP Plus ion trap mass spectrometer (San Jose, CA). The direct infusion flow-rate was $2.0 \mu \mathrm{L} / \mathrm{min}$. The electrospray source conditions were $2.5 \mathrm{kV}$ spray voltage and $120^{\circ} \mathrm{C}$ capillary temperature. In all experiments, the scanned mass range was set at 500-3000 u. Thermal difference ESI mass spectra were obtained by increasing capillary temperature of the electrospray ion source from $60{ }^{\circ} \mathrm{C}$ to $400{ }^{\circ} \mathrm{C}$. With the capillary temperature of $60^{\circ} \mathrm{C}$ as the origin of fits, the normalized intensities of the G-quadruplex and their 1:1 complex ions were plotted as a function of temperature, and the transition curves for the dissociation were obtained. The MS/MS spectra were obtained by collision-induced dissociation (CID) after isolation of the precursor ion, the collision conditions were maintained at normalized collision energy of $0 \% \sim 16 \%$.

\section{Circular Dichroism}

The CD spectra of DNA were measured using a J-810 spectropolarimeter (JASCO Ltd., Tokyo, Japan) with a $0.1 \mathrm{~cm}$ path-length quartz cell at $25^{\circ} \mathrm{C}$. The concentration of DNA samples was $10 \mu \mathrm{M}$.

\section{Results and Discussion}

\section{Novel Dimeric G-Quadruplexes of HIV-1 Integrase Inhibitors}

The ESI mass spectra of S1 and S2 in methanol/water (25:75, vol/vol) (Figure 1a and b) show that the most intense peaks are $\left[\mathrm{S} 1-6 \mathrm{H}^{+}\right]^{6-}$ and $\left[\mathrm{S} 2-6 \mathrm{H}^{+}\right]^{6-}$, corresponding to single-strand ions. However, ESI mass spectra from ammonium acetate solution show the dominant peaks for two-strand ions with five $\mathrm{NH}_{4}^{+}$, such as $\left[2 \times \mathrm{S} 1+5 \mathrm{NH}_{4}^{+}-11 \mathrm{H}^{+}\right]^{6-}$ and $[2 \times \mathrm{S} 2+$ $\left.5 \mathrm{NH}_{4}^{+}-11 \mathrm{H}^{+}\right]^{6-}$ at $m / z 1714.1$ and 1815.3 for S1 and S2, respectively (Figure $1 \mathrm{c}$ and $\mathrm{d}$ ).

CD spectra of S1 and S2 were analyzed by titrating with $\mathrm{NH}_{4}^{+}$and $\mathrm{K}^{+}$from 0 to $100 \mathrm{mM}$ (Figure 2). In $\mathrm{KCl}, \mathrm{NH}_{4} \mathrm{OAc}$ and $\mathrm{CH}_{3} \mathrm{OH} / \mathrm{H}_{2} \mathrm{O}$, a positive peak at $264 \mathrm{~nm}$ and a negative peak at $240 \mathrm{~nm}$ are shown in the CD spectra for S1 and S2, which confirm the formation of G-quadruplex by the characteristics structures with parallel orientation of the strands $[29,30]$.

Both CD and ESI-MS results demonstrate the intramolecular G-quadruplex formations in the methanol/water (25:75, vol/vol) solution, as well as the dimeric Gquadruplex formations in the $100 \mathrm{mM} \mathrm{NH}_{4} \mathrm{OAc}$ solution. Since cations are known to sit between each G-tetrad layer to stabilize G-quadruplex structure, it would be reasonable that there are six tetrad layers in S1 and S2 dimeric G-quadruplexes possessing five $\mathrm{NH}_{4}^{+}$ ions [27]. 

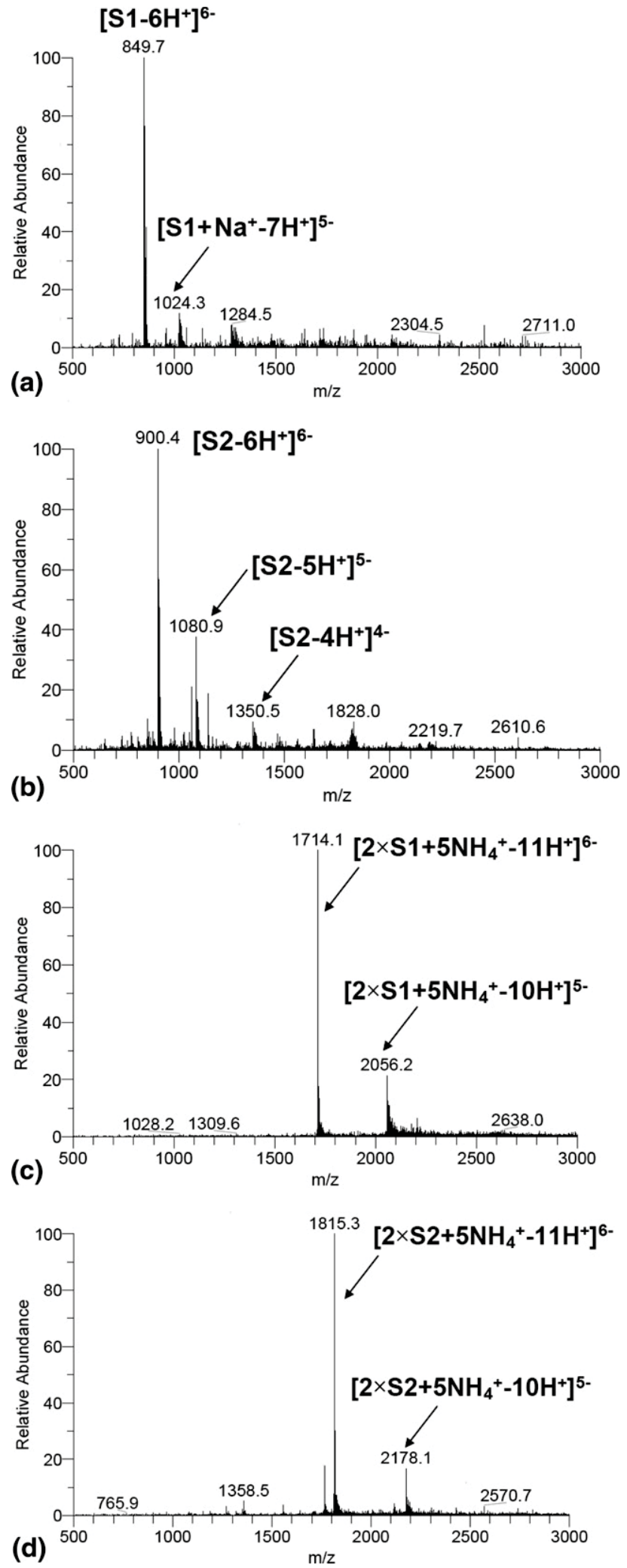

Figure 1. ESI mass spectra of $\mathrm{S} 1$ and $\mathrm{S} 2(\mathbf{a})$ and (b) in methanol/ water (25:75, vol/vol); (c) and (d) in $100 \mathrm{mM} \mathrm{NH} \mathrm{m}_{4} \mathrm{OAc}$ buffer $(\mathrm{pH}=7.0)$.

\section{Complex of the Dimeric G-Quadruplex and Binding Molecules}

To examine the recognition function of the binding molecules, perylene derivative (Tel03), ImImIm $\beta D p$, PyPyPy $\beta$ Dp, and macrocyclic phosphoramidates, the affinity and stoichiometry were studied by mixing of the S1 and S2 dimeric G-quadruplex with binding molecules, respectively, at different concentrations using ESI-MS. Figure 3 shows the part of mass spectra of $\mathrm{S} 1$ and binding molecules as an example $\left[\mathrm{D}^{n-}\right.$ denotes dimeric G-quadruplex ion with $-n$ charges, [D + $\mathrm{mPi}]^{\mathrm{n}-}$ denotes 1:m complex ion of the dimeric Gquadruplex and binding molecule (Pi) with $-n$ charges $(\mathrm{m}=1,2 ; n=5,6 ; \mathrm{i}=1,2, \ldots, 5)]$.

For Tel03 (Figure 3a), the 1:1 complex ion at $\mathrm{m} / \mathrm{z}$ 1807.3 is the base peak $(100 \%)$, and the intensity of $1: 2$ complex ion at $\mathrm{m} / \mathrm{z} 1900.6$ is $85 \%$. In the case of $\operatorname{ImImIm} \beta D p$, the base peak is $1: 1$ complex ion at $\mathrm{m} / \mathrm{z}$ 1802.7 , and the free G-quadruplex and 1:2 complex ions at $\mathrm{m} / \mathrm{z} 1714.1$ and 1890.5 have relative intensities of $20 \%$ and $58 \%$, respectively (Figure $3 \mathrm{~b}$ ). So Tel03 and $\operatorname{ImImIm} \beta \mathrm{Dp}$ have a clear preference for $1: 1$ and $1: 2$ complexes. In the case of PyPyPy $\beta \mathrm{Dp}$, the 1:1 complex ion at $m / z 1801.0$ is $61 \%$ as intense as the base peak of the G-quadruplex ion at $\mathrm{m} / \mathrm{z} 1714.0$ (Figure 3c). As for
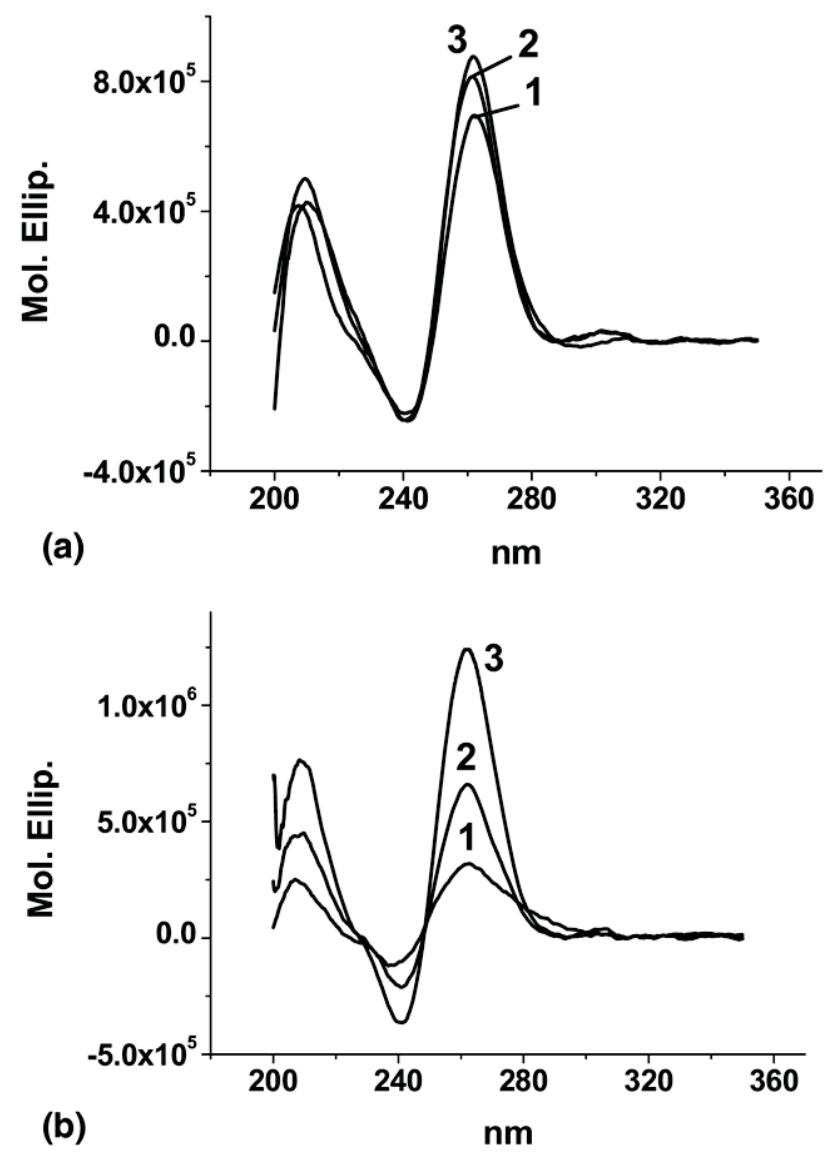

Figure 2. CD spectra of $\mathrm{S} 1$ (a) and $\mathrm{S} 2$ (b) in (1) methanol/water (25:75, vol/vol), (2) $100 \mathrm{mM} \mathrm{NH} \mathrm{OAA}_{4}$ and (3) $100 \mathrm{mM} \mathrm{KCl}$. 

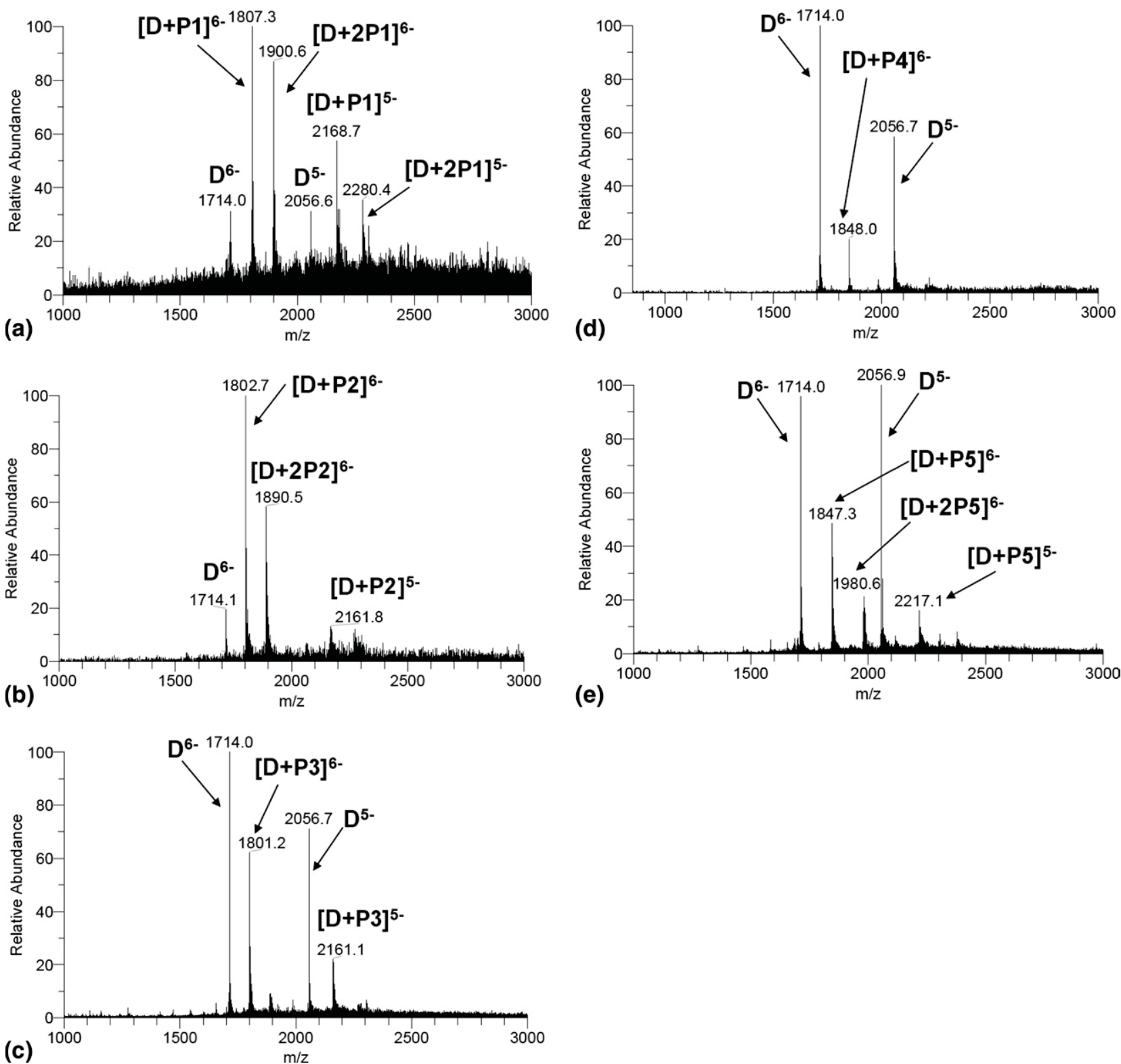

Figure 3. ESI mass spectra of $10.0 \mu \mathrm{M}$ S1 with $5.0 \mu \mathrm{M}$ binding molecules. (a) Te103 (P1), (b) $\operatorname{ImImIm} \beta$ Dp (P2), (c) PyPyPy $\beta$ Dp (P3), (d) Dpku-13 (P4), and (e) Dpku-14 (P5).

Dpku-13, the trans- side chain isomer, the 1:1 complex ion with $6-$ charge state at $m / z 1848.0$ has relative intensity of $21 \%$ (Figure $3 \mathrm{~d}$ ). However, the intensities of 1:1 and 1:2 complex ions of Dpku-14 (the cis-side chain isomer) at $\mathrm{m} / \mathrm{z} 1847.3$ and 1980.6 are $48 \%$ and $21 \%$, respectively (Figure 3e). Therefore, Dpku-14 is more suitable for binding the G-quadruplex of S1 than the Dpku-13. The results for corresponding experiment with S2 show that Tel03 and ImImIm $\beta$ Dp have specificity with both $1: 1$ and 1:2 binding stoichiometry (Figure S1 in Supplementary Material).

The relative binding affinities from 2.5 to $20.0 \mu \mathrm{M}$ binding molecules were examined by ESI mass spectrometry. Here, a parameter, $\mathrm{IR}_{\mathrm{a}}$ (relative intensity ratio of all complex ions to the sum of free G-quadruplex and its complex ions in ESI spectrum, subscript "a" in $\mathrm{IR}_{a}$ denote affinity), is used for analysis of the relative binding affinities of the binding molecules to the dimeric G-quadruplex.

$$
\begin{aligned}
& \text { IRa } \\
& =\frac{\sum \mathrm{I}_{\mathrm{r}}(\mathrm{D}+\mathrm{Pi})+\sum \mathrm{I}_{\mathrm{r}}(\mathrm{D}+2 \mathrm{Pi})+\sum \mathrm{I}_{\mathrm{r}}(\mathrm{D}+3 \mathrm{Pi})}{\sum \mathrm{I}_{\mathrm{r}}(\mathrm{D})+\sum \mathrm{I}_{\mathrm{r}}(\mathrm{D}+\mathrm{Pi})+\sum \mathrm{I}_{\mathrm{r}}(\mathrm{D}+2 \mathrm{Pi})+\sum \mathrm{I}_{\mathrm{r}}(\mathrm{D}+3 \mathrm{Pi})} \times 100 \%
\end{aligned}
$$

where $\Sigma I_{r}(D), \sum I_{r}(D+P i), \sum I_{r}(D+2 P i)$, and $\Sigma I_{r}(D+$ 3Pi) are the total intensities of dimeric G-quadruplexes (D), 1:1, 1:2, and 1:3 complex ions (D + mPi) with 6and $5-$ charges, respectively.

Table 1 lists the values of $\operatorname{IR}_{\mathrm{a}}$ at $2.5 \mu \mathrm{M}, 5.0 \mu \mathrm{M}, 10.0$ $\mu \mathrm{M}$, and $20.0 \mu \mathrm{M}$ binding molecules to the dimeric G-quadruplex. These data show that the order of rela- 
Table 1. The relative intensity ratio, $\mathrm{IR}_{\mathrm{a}}(\%)$, of $\mathrm{S} 1$ with binding molecules ${ }^{\mathrm{a}}$

\begin{tabular}{|c|c|c|c|c|c|c|c|c|}
\hline \multirow[b]{2}{*}{$\mathrm{Pi}$} & \multicolumn{2}{|c|}{$2.5 \mu \mathrm{M}$} & \multicolumn{2}{|c|}{$5.0 \mu \mathrm{M}$} & \multicolumn{2}{|c|}{$10.0 \mu \mathrm{M}$} & \multicolumn{2}{|c|}{$20.0 \mu \mathrm{M}$} \\
\hline & $\mathrm{IR}_{\mathrm{a}}(\%)$ & SD & $\operatorname{IR}_{\mathrm{a}}(\%)$ & SD & $\operatorname{IR}_{a}(\%)$ & SD & $\mathrm{IR}_{\mathrm{a}}(\%)$ & SD \\
\hline Tel03 & 55 & 9.2 & 82 & 5.3 & 85 & 2.2 & 93 & 0.1 \\
\hline $\operatorname{lm} / \mathrm{m} / \mathrm{m} \beta \mathrm{Dp}$ & 71 & 10 & 88 & 0.1 & 98 & 0.1 & 98 & 0.2 \\
\hline РyPyРy $\beta$ Dp & 17 & 8.3 & 40 & 3.5 & 71 & 0.3 & 84 & 0.1 \\
\hline Dpku-13 & 2.2 & 0.1 & 19 & 6.8 & 26 & 12 & 33 & 17 \\
\hline Dpku-14 & 11 & 9.3 & 35 & 2.5 & 65 & 0.6 & 90 & 0.4 \\
\hline
\end{tabular}

${ }^{a}$ Value is the average of three measurements.

tive binding affinities is $\operatorname{ImImIm} \beta \mathrm{Dp}>\mathrm{Tel} 03>$ PyPyPy $\beta$ Dp $>$ Dpku-14 > Dpku-13.

CID studies on the complex ions of the dimeric G-quadruplex and binding molecules imply the nature of binding in molecules (Pi). The MS/MS spectra of the complex ions, $\left[2 \times \mathrm{S} 1+\mathrm{Pi}+5 \mathrm{NH}_{4}^{+}-12 \mathrm{H}^{+}\right]^{6-}$ were obtained at the normalized collision energy of $16 \%$. For the complex ion of Tel03, the intensity of the fragment ion with the loss of the binding molecule is only about $10 \%$, and the intensity of the ion by the loss of the guanine nucleobase is $57 \%$. In the case of $\operatorname{Im} \operatorname{ImIm} \beta \mathrm{Dp}$, the relative intensity of the fragment ion with the loss of the binding molecule is $71 \%$, much higher than that of Tel03 (Figure S4 in Supplementary Material). As for Dpku-13 and Dpku-14, the fragment ions at $\mathrm{m} / \mathrm{z}$ 1700.5, with the loss of the binding molecule, could be observed as the dominant peaks in the MS/MS spectra. According to the CID experiments, the binding between the dimeric G-quadruplex and Tel03 is more stable and stronger than that of other binding molecules. This may be due to the conjugate aromatic system in Tel03, which favors $\pi$-stacking with Gtetrads to stabilize the complexes.

\section{The Gas-Phase Thermostabilization of the Dimeric G-Quadruplex and Their Complex Ions}

To investigate the thermostabilization, ESI mass spectra were recorded for the analysis of the effect of the capillary temperature $\left(60^{\circ}-400{ }^{\circ} \mathrm{C}\right)$ on the dimeric Gquadruplex and their complexes. In the range of $60^{\circ}$ to $80^{\circ} \mathrm{C}$, the dimeric quadruplex is observed as the ammonium adduct $\left(\left[2 \times \mathrm{S} 1+5 \mathrm{NH}_{4}^{+}-11 \mathrm{H}^{+}\right]^{6-}, \mathrm{m} / \mathrm{z}\right.$ $1714)$, which is the most abundant $(100 \%)$ and stable. When the temperature is increased to $100^{\circ} \mathrm{C}$, the dimeric G-quadruplex ion dissociates and yields the fragment ion with loss of an ammonium ion $([2 \times \mathrm{S} 1+$ $\left.4 \mathrm{NH}_{4}^{+}-10 \mathrm{H}^{+}\right]^{6-}$ at $\left.\mathrm{m} / \mathrm{z} 1711\right)$. With the temperature raises higher, some ions are produced by the loss of more than one ammonium ion. The $\left[2 \times \mathrm{S} 1-6 \mathrm{H}^{+}\right]^{6-}$ ion at $\mathrm{m} / \mathrm{z} 1700$ dissociates into single-strand oligomers from $200{ }^{\circ} \mathrm{C}$ to $300{ }^{\circ} \mathrm{C}$, which has been proved by the MS/MS spectra. Increasing the temperature to $400{ }^{\circ} \mathrm{C}$ has a destructive effect on the backbone of the DNA, which yields some fragment ions, such as ions by the loss of the guanine nucleobases ([S1 $\left.-\mathrm{nG}-3 \mathrm{H}^{+}\right]^{3-}$, $n=1,2)$ at $m / z 1600$ and 1650 (Scheme 2).

In Figure $4 \mathrm{a}$ and $\mathrm{b}$, the normalized intensity of the ions, $\left[2 \times \mathrm{S} 1+5 \mathrm{NH}_{4}^{+}-11 \mathrm{H}^{+}\right]^{6-}$ and $\left[2 \times \mathrm{S} 2+5 \mathrm{NH}_{4}^{+}\right.$ $\left.-11 \mathrm{H}^{+}\right]^{6-}$, are plotted as a function of the capillary temperature $\left(60^{\circ}-400^{\circ} \mathrm{C}\right)$, and a transition curve for the dissociation are obtained. Here, the dissociation temperature $\left(\mathbf{T}_{50}\right)$ is assigned where the relative intensity of the ion in the ESI mass spectrum is $50 \%$. The plot shows how the dimeric G-quadruplex dissociation proceeds. The value of $\mathbf{T}_{50}$ is $187^{\circ} \mathrm{C}$ for $\mathrm{S} 1$, and $204^{\circ} \mathrm{C}$ for $\mathrm{S} 2$, which could be used to balance the thermostability of the dimeric G-quadruplexes and their complex ions.

Similarly, the temperature-dependent stability of the complex ions of the dimeric G-quadruplex was studied with the capillary temperature increased from $60{ }^{\circ} \mathrm{C}$ to $400{ }^{\circ} \mathrm{C}$. ESI-MS spectra indicate that the complex ions

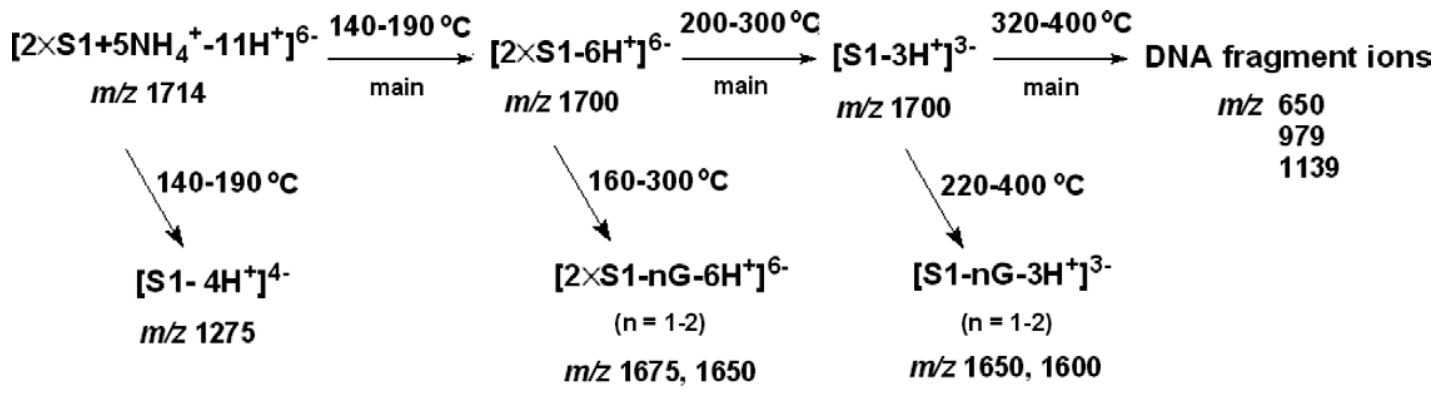

Scheme 2. The dissociation pathway of the dimeric G-quadruplex ion $\left[2 \times \mathrm{S} 1+5 \mathrm{NH}_{4}^{+}-11 \mathrm{H}^{+}\right]^{6-}$ with the temperature increased. The ranges of temperatures labeled above the arrows represent the temperature when the relative intensity of the product ions exceeded $10 \%$. "main" represents the main dissociation pathway. 

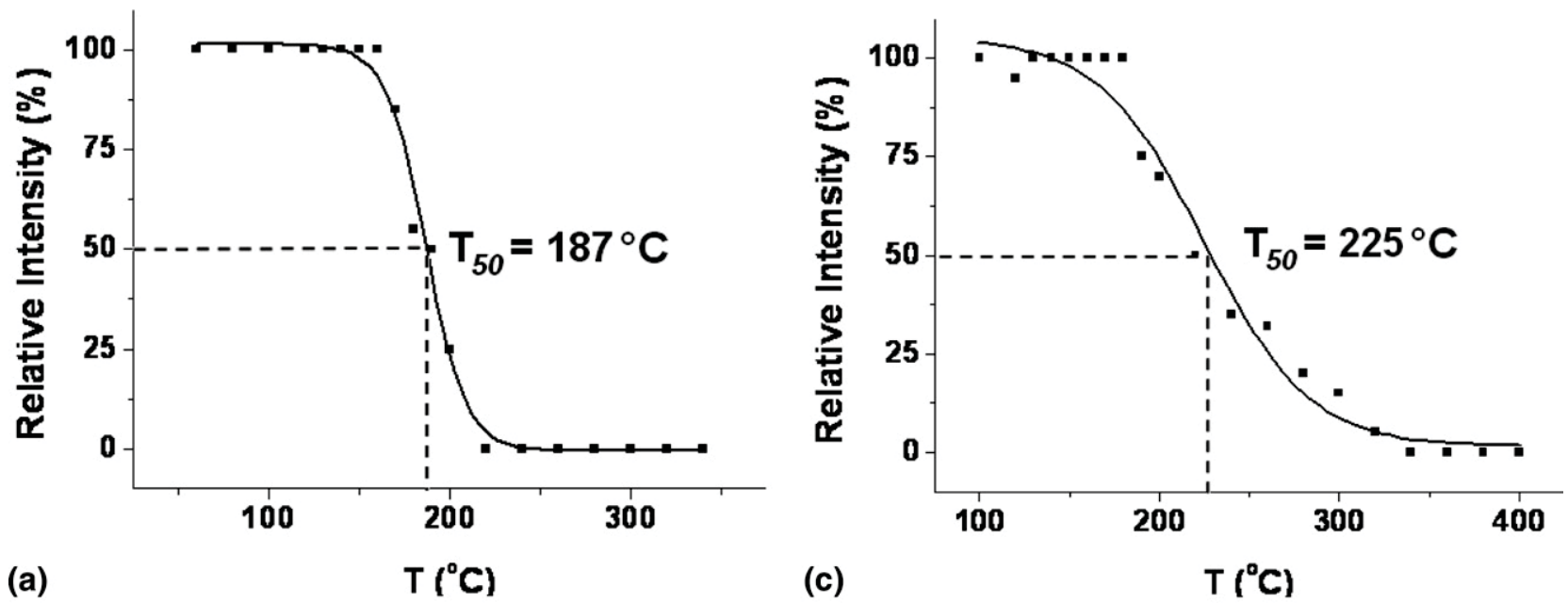

(a)

$\mathrm{T}\left({ }^{\circ} \mathrm{C}\right)$

(c)
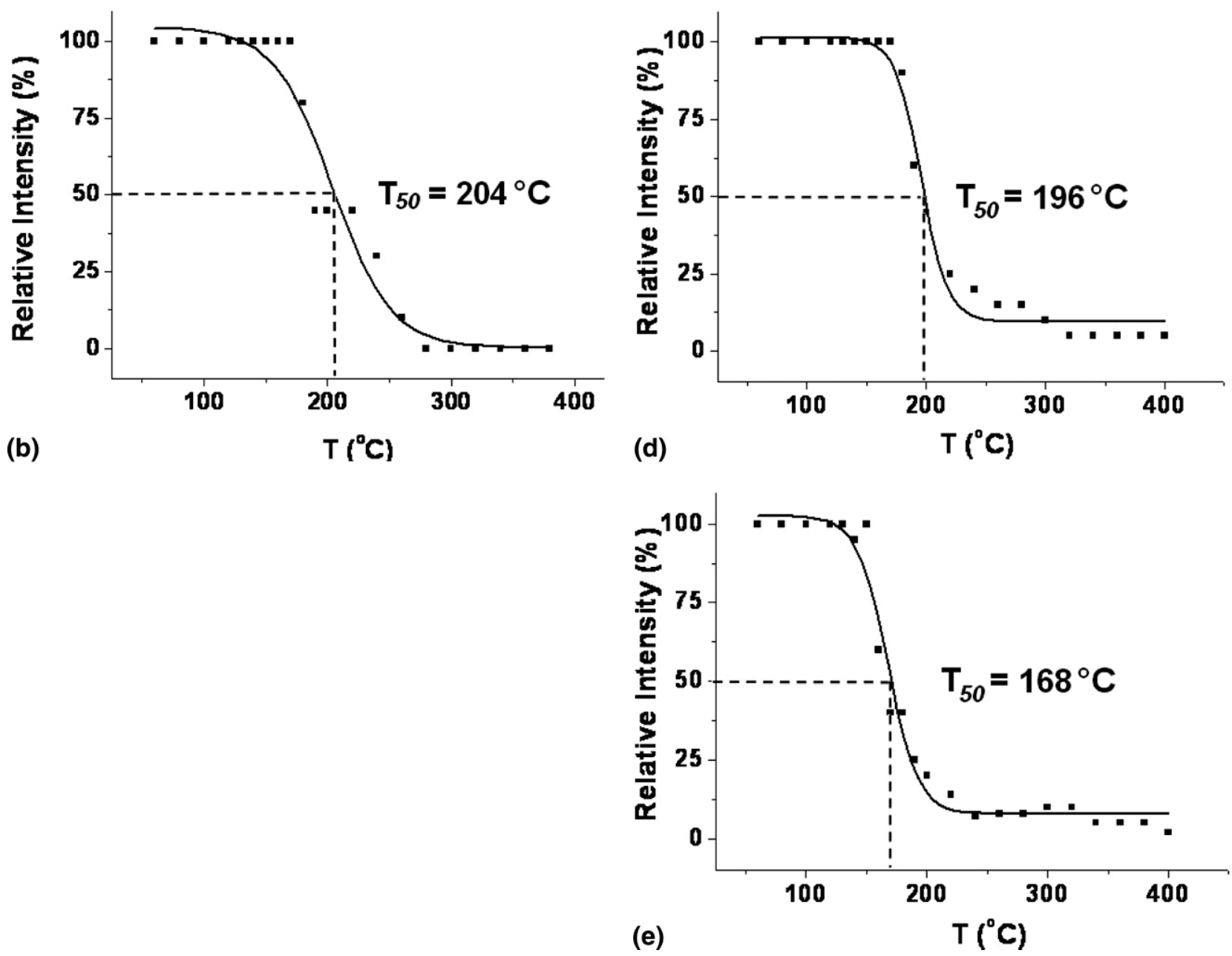

Figure 4. The transition curves for the thermal dissociation of the dimeric G-quadruplexes and their complexes. (a) $\left[2 \times \mathrm{S} 1+5 \mathrm{NH}_{4}^{+}-11 \mathrm{H}^{+}\right]^{6-}$; (b) $\left[2 \times \mathrm{S} 2+5 \mathrm{NH}_{4}^{+}-11 \mathrm{H}^{+}\right]^{6-}$; (c) $[2 \times \mathrm{S} 1+\mathrm{P} 1+$ $\left.5 \mathrm{NH}_{4}^{+}-11 \mathrm{H}^{+}\right]^{6-} ;$ (d) $\left[2 \times \mathrm{S} 1+\mathrm{P} 2+5 \mathrm{NH}_{4}^{+}-11 \mathrm{H}^{+}\right]^{6-}$, and $(\mathbf{e})\left[2 \times \mathrm{S} 1+\mathrm{P} 5+5 \mathrm{NH}_{4}^{+}-11 \mathrm{H}^{+}\right]^{6-}$.

lose ammonium ions and binding molecules when the capillary temperature is increased. Figure $4 c, d$, and e show the transition curves for the dissociation of the 1:1 complex ions of the S1 dimeric G-quadruplex with Pi as examples. For the complex ion of the dimeric G-qua- druplex with Tel03, the $\mathrm{T}_{50}$ value increases to $225^{\circ} \mathrm{C}$. $\operatorname{Im} \operatorname{Im} \operatorname{Im} \beta D p$ raises the $\mathrm{T}_{50}$ value to $196^{\circ} \mathrm{C}$. Dpku-14 decreases the $\mathrm{T}_{50}$ value to $168^{\circ} \mathrm{C}$. As a result, both Tel03 and ImImIm $\beta \mathrm{Dp}$ thermally stabilize the G-quadruplex DNA, with the extent of thermal enhancement being 

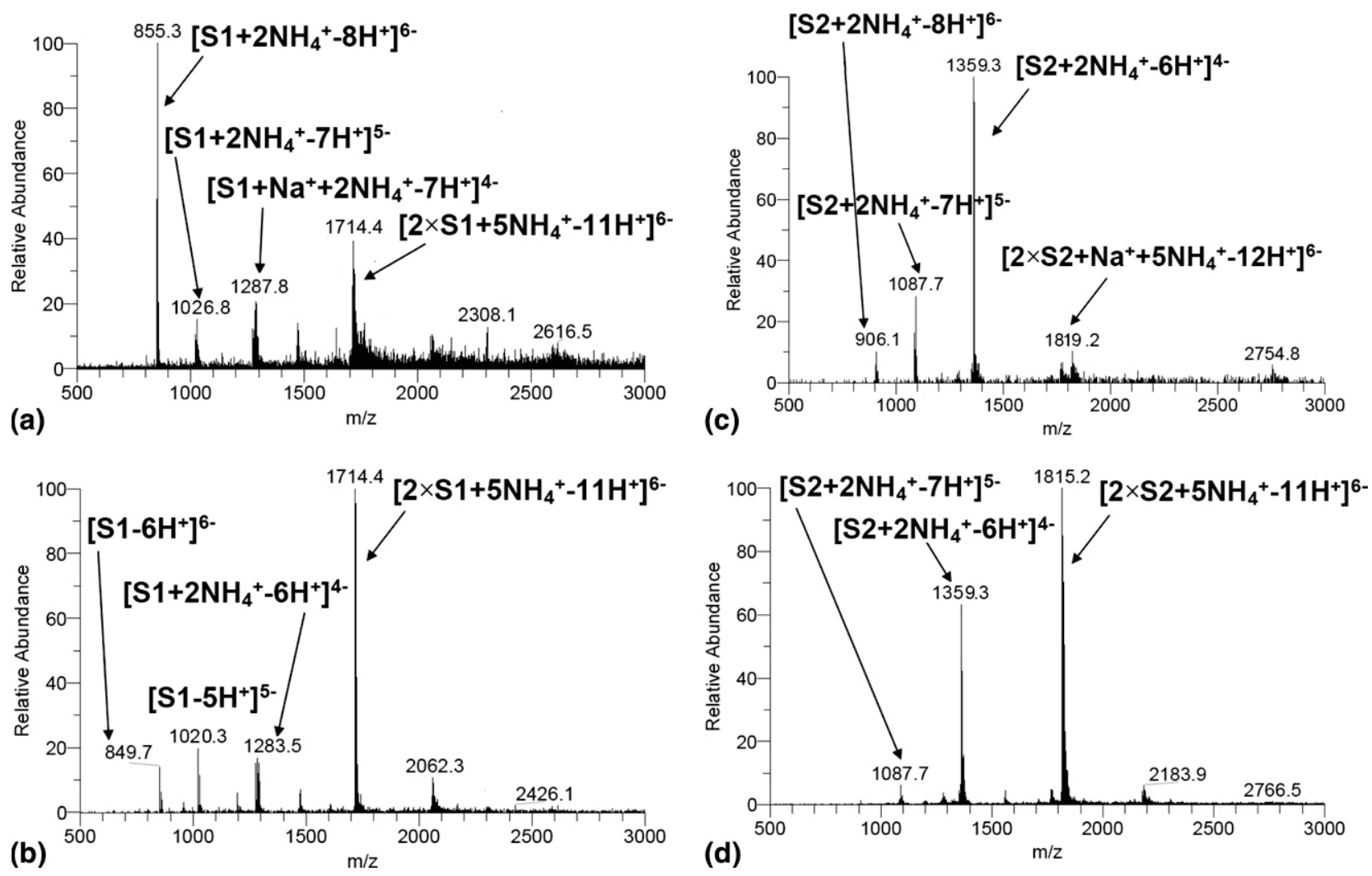

Figure 5. ESI mass spectra of equilibrium of intramolecular and dimeric G-quadruplexes. For S1 (a) $5.0 \mathrm{mM} \mathrm{NH}_{4} \mathrm{OAc}$; (b) $7.5 \mathrm{mM} \mathrm{NH}_{4} \mathrm{OAc}$; $\mathrm{S} 2$ (c) $10 \mathrm{mM} \mathrm{NH}_{4} \mathrm{OAc}$; and (d) $20 \mathrm{mM} \mathrm{NH}_{4} \mathrm{OAc}$.

greater for Tel03, while Dpku-14 decreases the thermal stability of the S1 G-quadruplex DNA.

\section{Equilibrium and Interconversion of Intramolecular and Dimeric G-Quadruplexes}

The equilibriums between the intramolecular and the dimeric G-quadruplexes under different conditions were unambiguously observed. The results from ESI-MS and CD had demonstrated the intramolecular G-quadruplex formations for S1 and S2 in methanol/ water $(25: 75, \mathrm{vol} / \mathrm{vol})$ solution. By contrast with the spectrum at $5.0 \mathrm{mM} \mathrm{NH}_{4} \mathrm{OAc}$, the addition of $7.5 \mathrm{mM}$ $\mathrm{NH}_{4} \mathrm{OAc}$ yields a larger proportion of the dimeric G-quadruplex ion with five ammonium ions (Figure 5a and b). At this point, the intensity of the intramolecular G-quadruplex decreases to less than $50 \%$ as intense as the base peak of the dimeric G-quadruplex. Therefore, the apparent intense peak for $\mathrm{S} 1$ is from the intramolecular G-quadruplex ion at $5.0 \mathrm{mM} \mathrm{NH}_{4} \mathrm{OAc}$, and the intensity of the intramolecular G-quadruplex decreases with increased concentration of $\mathrm{NH}_{4} \mathrm{OAc}$. When the concentration of $\mathrm{NH}_{4} \mathrm{OAc}$ is increased to $10 \mathrm{mM}$, the equilibrium shifts further to the dimeric G-quadruplex.

The mass spectrum for S2 indicates that the base peak is the intramolecular G-quadruplex with 4charge state, coordinated two $\mathrm{NH}_{4}^{+}$ions at $10 \mathrm{mM}$ ammonium acetate (Figure 5c). Both of the intramolec- ular and dimeric G-quadruplex of S2 could apparently be present at $20 \mathrm{mM}$ ammonium acetate, and the equilibrium shifts to the dimeric G-quadruplex. At this point, the intensity of the intramolecular G-quadruplex ion with 4 - charge state is $65 \%$, and the base peak is the dimeric G-quadruplex ion at the 6-charge state with five ammonium ions (Figure 5d).

The results from the CD spectra and ESI mass spectra of DNA solutions in different conditions demonstrate that both the S1 and S2 could form the intramolecular Gquadruplex structure spontaneously in methanol/water (25:75, vol/vol) solution. The addition of $\mathrm{NH}_{4}^{+}$could induce the structural transition from the intramolecular G-quadruplex to the stable dimeric G-quadruplex.

The effect of other factors, such as pH, DNA concentration, and the interaction with the binding molecules on the equilibrium and interconversion of the two G-quadruplex conformations were also investigated. First, the role of $\mathrm{pH}$ on the two G-quadruplex forms transition was examined. For the S2, the intramolecular and the dimeric G-quadruplexes could both be present at $20 \mathrm{mM}$ ammonium acetate $(\mathrm{pH}$ 6.5) (Figure $5 \mathrm{~d}$ ). However, when the $\mathrm{pH}$ is changed to 4.0 , the equilibrium shifts to the intramolecular G-quadruplex formation, the ion corresponding to the single strand is the base peak $\left(\left[\mathrm{S} 2-4 \mathrm{H}^{+}\right]^{4-}, \mathrm{m} / \mathrm{z} 1351.4\right)$, while the intensity of $\left[2 \times \mathrm{S} 2+5 \mathrm{NH}_{4}^{+}-11 \mathrm{H}^{+}\right]^{6-}$ is decreased to $32 \%$. This finding implies that the acidic condition ( $\mathrm{pH} 4.0)$ is 
Table 2. The relative intensities of free and complexes of the intramolecular and the dimeric G-quadruplexes (S1) in ESI mass spectra $^{\mathrm{ab}}$

\begin{tabular}{lccccccc}
\hline & Free S1 & S1 + Tel03 & S1 + Imlmlm $\beta$ Dp & & Free S1 & S1 + Tel03 & S1 + Imlmlm $\beta$ Dp \\
\hline \hline$[\mathrm{M}]^{6-}$ & 20 & 13 & N.D. $^{\mathrm{c}}$ & {$[\mathrm{D}]^{7-}$} & 10 & N.D. & N.D. \\
{$[\mathrm{M}+\mathrm{Pi}]^{6-}$} & N.D. & N.D. & N.D. & {$[\mathrm{D}+\mathrm{Pi}]^{7-}$} & N.D. & 13 & N.D. \\
{$[\mathrm{M}]^{5-}$} & 24 & N.D. & 5 & {$[\mathrm{D}+2 \mathrm{Pi}]^{7}$} & N.D. & 18 & N.D. \\
{$[\mathrm{M}+\mathrm{Pi}]^{5-}$} & N.D. & 18 & 20 & {$[\mathrm{D}]^{6-}$} & 100 & 16 & N.D. \\
{$[\mathrm{M}+2 \mathrm{Pi}]^{5-}$} & N.D. & N.D. & 47 & {$[\mathrm{D}+\mathrm{Pi}]^{6-}$} & N.D. & 50 & 8 \\
{$[\mathrm{M}]^{4-}$} & 42 & N.D. & N.D. & {$[\mathrm{D}+2 \mathrm{Pi}]^{6}$} & N.D. & 100 & 19 \\
{$[\mathrm{M}+\mathrm{Pi}]^{4-}$} & N.D. & 20 & 22 & {$[\mathrm{D}]^{5-}$} & 16 & 12 & N.D. \\
{$[\mathrm{M}+2 \mathrm{Pi}]^{4-}$} & N.D. & N.D. & 100 & {$[\mathrm{D}+\mathrm{Pi}]^{5-}$} & N.D. & 20 & 14 \\
{$[\mathrm{M}+3 \mathrm{Pi}]^{4-}$} & N.D. & N.D. & 8 & [D+2Pi $]^{5}$ & N.D. & 35 & N.D. \\
\hline
\end{tabular}

${ }^{a}[M]^{n-}$ and $[M+m P i]^{n-}(n=4,5,6 ; m=1,2,3)$ are the free and the complex forms of the intramolecular G-quadruplexes, respectively; while $[D]^{n-}$ and $[D+m P i]^{n-}(n=5,6,7 ; m=1,2)$ are the free and the complex forms of the dimeric G-quadruplexes, respectively.

${ }^{b}$ Effect of binding molecule $(\mathrm{Pi})$ on the equilibrium between the intramolecular and the dimeric G-quadruplexes at a molar ratio of $1: 1$.

${ }^{\mathrm{c}}$ N.D. $=$ not detectable.

not favorable for the dimeric G-quadruplex formation. Besides, the ESI mass spectra of the S2 at the basic solutions $(\mathrm{pH}>7.0)$, which are similar to that of the solution at $\mathrm{pH} 6.5$, show that the basic condition favors the dimeric G-quadruplex formation (Figure S2 in Supplementary Material). Similarly, the change of $\mathrm{pH}$ from 4.0 to 10.0 could induce a structural conversion from the intramolecular to the dimeric G-quadruplex in the S1 solution.

Next, the influence of the DNA concentration $(0.25-50.0 \mu \mathrm{M})$ on the interconversion of the two G-quadruplex formations was examined. As for S2, with a DNA concentration of $0.25 \mu \mathrm{M}$, the intensity of the intramolecular G-quadruplex ([S2 $+2 \mathrm{NH}_{4}^{+}-$ $\left.6 \mathrm{H}^{+}\right]^{4-}, \mathrm{m} / \mathrm{z}$ 1358.0) is much higher than that of the dimeric G-quadruplex $\left(\left[2 \times \mathrm{S} 2+5 \mathrm{NH}_{4}^{+}-11 \mathrm{H}^{+}\right]^{6-}, \mathrm{m} / \mathrm{z}\right.$ 1815.5). As the concentration of DNA is increased to 5.0 $\mu \mathrm{M}$, the equilibrium shifts to the dimeric G-quadruplex structure, and the base peak would be changed to that of the dimer with five $\mathrm{NH}_{4}^{+}$ions $\left(\left[2 \times \mathrm{S} 2+5 \mathrm{NH}_{4}^{+}-\right.\right.$ $\left.11 \mathrm{H}^{+}\right]^{6-}, m / z$ 1814.6) (Figure S3 in Supplementary Material). Similarly, when the concentration of S1 is increased from $0.5 \mu \mathrm{M}$ to $5.0 \mu \mathrm{M}$, it favors the dimeric G-quadruplex formation. Therefore, the increase of the concentration of DNA could induce the conformational transition from the intramolecular to the dimeric Gquadruplex for S1 and S2.

Third, the effect of the binding molecules (Pi), a perylene derivative (Tel03), $\operatorname{Im} \operatorname{Im} \operatorname{Im} \beta \mathrm{Dp}$, and PyPyPy $\beta$ Dp, on the interconversion was investigated by ESI mass spectrometry. The results show that Tel03 and $\operatorname{Im} \operatorname{Im} \operatorname{Im} \beta \mathrm{Dp}$ are very efficient for inducing the interconversion between the intramolecular and the dimeric G-quadruplexes. In this study, the concentration of the binding molecules was increased steadily from zero to $10.0 \mu \mathrm{M}$, while the concentration of S1 was remained at $10.0 \mu \mathrm{M}$. Table 2 shows that Tel03 leads to a significant intensity of the 1:1 and 1:2 complexes with the dimeric G-quadruplex in the ESI mass spectrum. This finding implies that Tel03 favors the dimeric G-quadruplex complexes. An apparent preference of $\operatorname{Im} \operatorname{Im} \operatorname{Im} \beta \mathrm{Dp}$ for the intramolecular G-quadruplex com- plex over the dimeric complex is also found; the dominant peaks correspond to 1:2 complex ions with $4-$ and 5- charge states (Table 2).

Here, the intensity ratio of the dimeric G-quadruplex and its complex ions to the intramolecular G-quadruplex and its complex ions was introduced as a parameter, $\mathrm{IR}_{\mathrm{s}}$, to compare binding selectivity of $\mathrm{Pi}$ to the two G-quadruplex formations (dimeric and intramolecular G-quadruplexes, subscript " $s$ " in $\mathrm{IR}_{\mathrm{s}}$ denote binding selectivity).

$$
\mathrm{IRs}=\frac{\sum \mathrm{I}_{\mathrm{r}}(\mathrm{D})+\sum \mathrm{I}_{\mathrm{r}}(\mathrm{D}+\mathrm{mPi})}{\sum \mathrm{I}_{\mathrm{r}}(\mathrm{M})+\sum \mathrm{I}_{\mathrm{r}}(\mathrm{M}+\mathrm{mPi})}
$$

where $\Sigma I_{r}(D)$ and $\Sigma I_{r}(D+m P i)$ are the total intensities of the free and the complex of the dimeric Gquadruplexes, respectively, while $\Sigma I_{r}(M)$ and $\Sigma I_{r}(M+$ $\mathrm{mPi}$ ) are the total intensities of the free and the complex of the intramolecular G-quadruplexes, respectively.

Thus, $\mathrm{IR}_{\mathrm{s}}$ could be obtained for the selectivity of the binding molecules to the two G-quadruplex forms. If the value of $I R_{s}$ increases when the binding molecule is added to the equilibrium system, this implies that this binding molecule shifts the equilibrium to the dimeric G-quadruplex formation and induces a structural change from the intramolecular to the dimeric Gquadruplex. The $\mathrm{IR}_{\mathrm{s}}$ values of the binding molecules for $\mathrm{S} 1$ have been calculated by formula [2]. Compared to $\mathrm{IR}_{\mathrm{s}}$ of $\mathrm{S} 1$ (1.81), Tel03 shows a 3.52-fold increase in the value of $\mathrm{IR}_{\mathrm{s}}(5.18)$ when the concentration of Tel03 is increased from $1.25 \mu \mathrm{M}$ to $10.0 \mu \mathrm{M}$ (Table 3), showing a structural selectivity for the dimeric G-quadruplex. That is, the intramolecular G-quadruplex could be effectively converted to the dimeric G-quadruplex. Contrarily,

Table 3. The intensity ratio $\left(\mathrm{IR}_{\mathrm{s}}\right)$ of the $\mathrm{S} 1$

\begin{tabular}{ccccc}
\hline $\begin{array}{c}\text { Concentration of } \mathrm{Pi} \\
(\mu \mathrm{M})\end{array}$ & 1.25 & 2.50 & 5.00 & 10.0 \\
\hline \hline Tel03 & 1.81 & 2.05 & 2.32 & 5.18 \\
Imlmlm $\beta \mathrm{Dp}$ & 2.18 & 0.86 & 0.36 & 0.20 \\
\hline
\end{tabular}




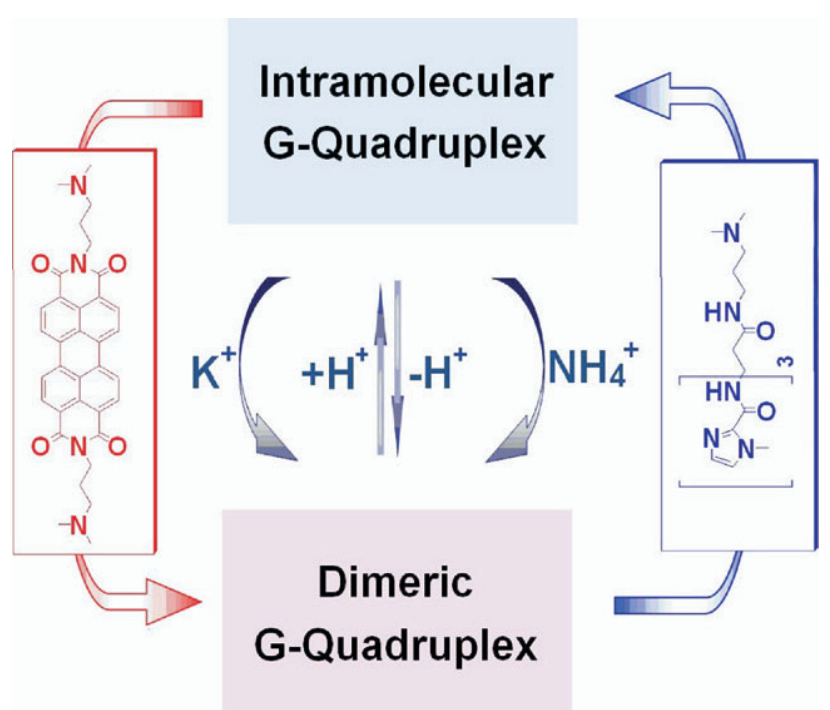

Figure 6. Sketch map for the conversion between the intramolecular G-quadruplex and the dimeric G-quadruplex for the S1.

$\operatorname{Im} \operatorname{Im} I m \beta D p$ shows a steady decrease in the value of $\mathbb{R}_{\mathrm{s}}$ from 2.18 to 0.20 when the concentration of $\operatorname{Im} \operatorname{Im} \operatorname{Im} \beta \mathrm{Dp}$ is increased from 1.25 to $10.0 \mu \mathrm{M}$ (Table 3). Therefore, $\operatorname{ImImIm} \beta$ Dp converts the dimeric G-quadruplex into the intramolecular G-quadruplex, resulting in strong and selective binding to this intramolecular G-quadruplex (Figure 6).

\section{Conclusions}

The present work has demonstrated that the formation and interconversion of the novel dimeric G-quadruplexes of $\mathrm{d}$ (GGGTGGGTGGGTGGGT) and d(GTGGTGGGTGGGTGGGT), the inhibitors of potent nanomolar HIV-1 integrase, were induced by $\mathrm{NH}_{4}^{+}$or $\mathrm{K}^{+}, \mathrm{pH}$, DNA concentration, and binding molecules. We have identified the specific binding of Tel03 and $\operatorname{Im} \operatorname{Im} \operatorname{Im} \beta \mathrm{Dp}$ in a system consisting of intramolecular and dimeric G-quadruplex formations of HIV-1 integrase inhibitors, which suggested that Tel03 could shift the equilibrium to form the dimeric G-quadruplex, while $\operatorname{Im} \operatorname{Im} \operatorname{Im} \beta D p$ induced preferentially a structural change from the dimeric to the intramolecular Gquadruplex, and could shift the equilibrium to formation of the intramolecular G-quadruplex. Besides the binding molecules, both Tel03 and $\operatorname{ImImIm} \beta$ Dp are in favor of the thermal stabilizations of the dimeric G-quadruplex structures.

\section{Acknowledgment}

We thank Mr. Jian Yuan for the helpful discussion and contribution in writing the paper.

\section{References}

1. Katz, R. A.; Skalka, A. M. The Retroviral Enzymes. Annu. Rev. Biochem. 1994, 63, 133-173.
2. Vink, C.; Plasterk, R. H. A. The Human-Immunodeficiency-Virus Integrase Protein. Trends Genet. 1993, 9, 433-437.

3. Declercq, E. Toward Improved Anti-HIV Chemotherapy: Therapeutic Strategies for Intervention with HIV Infections. J. Med. Chem. 1995, 38, 2491-2517.

4. Craigie, R. HIV Integrase, a Brief Overview from Chemistry to Therapeutics. J. Biol. Chem. 2001, 276, 213-216.

5. Katzman, M.; Katz, R. A. Substrate Recognition by Retroviral Integrases. Adv. Virus Res. 1999, 52, 371-395.

6. Asante-Applah, E.; Skalka, A. M. HIV-1 Integrase: Structural Organization, Conformational Changes, and Catalysis. Adv. Virus Res. 1999, 52, 351-369.

7. Neamati, N.; Marchand, C.; Pommier, Y. HIV-1 Integrase Inhibitors: Past, Present, and Future. Adv. Pharmacol. 2000, 49, 147-156.

8. Tarrago-Litvak, L.; Andreola, M. L.; Fournier, M.; Nevinsky, G. A.; Parissi, V.; de Soultrait, V. R.; Litvak, S. Inhibitors of HIV-1 Reverse Transcriptase and Integrase: Classical and Emerging Therapeutical Approaches. Curr. Pharm. Des. 2002, 8, 595-614.

9. Rando, R. F.; Ojwang, J.; Elbaggari, A.; Reyes, G. R.; Tinder, R.; McGrath, M. S.; Hogan, M. E. Suppression of Human-immunodeficiency-Virus Type-1 Activity in vitro by Oligonucleotides which Form Intramolecular Tetrads. J. Biol. Chem. 1995, 270, 1754-1760.

10. Mazumder, A.; Neamati, N.; Ojwang, J. O.; Sunder, S.; Rando, R. F.; Pommier, Y. Inhibition of the Human Immunodeficiency Virus Type I Integrase by Guanosine Quartet Structures. Biochemistry 1996, 35, 762-771.

11. Jing, N.; De Clercq, E.; Rando, F. R.; Pallansch, L.; Lackman- Smith, C.; Lee, S.; Hogan, M. E. Stability-Activity Relationships of a Family of G-Tetrad Forming Oligonucleotides as Potent HIV Inhibitors-A Basis for Anti-HIV Drug Design. J. Biol. Chem. 2000, 275, 3421-3430.

12. Jing, N.; Rando, R. F.; Pommier, Y.; Hogan, M. E. Ion Selective Folding of Loop Domains in a Potent Anti-HIV Oligonucleotide. Biochemistry $1997,36,498-505$.

13. Jing, N.; Marchand, C.; Liu, J.; Mitra, R.; Hogan, M. E.; Pommier, Y. Mechanism of Inhibition of HIV-1 Integrase by G-tetrad-forming Oligonucleotides in Vitro. J. Biol. Chem. 2000, 275, 460-467.

14. Jing, N.; Gao, X.; Rando, R. F.; Hogan, M. E. Potassium-Induced Loop Conformational Transition of a Potent Anti-HIV Oligonucleotide. J. Biomol. Struct. Dyn. 1997, 15, 573-585.

15. De Soultrait, V. R.; Lozach, P. Y.; Altmeyer, R.; Tarrago-Litvak, L.; Litvak, S.; Andreola, M. L. DNA Aptamers Derived from HIV-1 RNase $\mathrm{H}$ Inhibitors are Strong Anti-integrase Agents. J. Mol. Biol. 2002, 324, 195-203.

16. Mazzitelli, C. L.; Brodbelt, J. S.; Kern, J. T.; Rodriguez, M.; Kerwin, S. M. Evaluation of Binding of Perylene Diimide and Benzannulated Perylene Diimide Ligands to DNA by Electrospray Ionization Mass Spectrometry. J. Am. Soc. Mass Spectrom. 2006, 17, 593-604.

17. David, W. M.; Brodbelt, J.; Kerwin, S. M.; Thomas, P. W. Investigation of Quadruplex Oligonucleotide-drug Interactions by Electrospray Ionization Mass Spectrometry. Anal. Chem. 2002, 74, 2029-2033.

18. Anantha, N. V.; Azam, M.; Sheardy, R. D. Porphyrin Binding to Quadruplexed T4G4. Biochemistry 1998, 37, 2709-2714.

19. Jing, N.; Hogan, M. E. Structure-Activity of Tetrad-Forming Oligonucleotides as a Potent Anti-HIV Therapeutic Drug. J. Biol. Chem. 1998, 273, 992-999.

20. Phan, A. T.; Kuryavyi, V.; Ma, J. B.; Faure, A.; Andreola, M. L.; Patel, D. J. An Interlocked Dimeric Parallel-stranded DNA Quadruplex: A Potent Inhibitor of HIV-1 Integrase. Proc. Natl. Acad. Sci. U.S.A. 2005, 102, 634-639.

21. Crnugelj, M.; Sket, P.; Plavec, J. Small Changes in a G-Rich Sequence, a Dramatic Change in Topology: New Dimeric G-Quadruplex Folding Motif with Unique Loop Orientations. J. Am. Chem. Soc. 2003, 125, 7866-7871.

22. Baker, E. S.; Bernstein, S. L.; Gabelica, V.; De Pauwb, E.; Bowers, M. T. G-Quadruplexes in Telomeric Repeats are Conserved in a Solvent-Free Environment. Int. J. Mass Spectrom. 2006, 253, 225-237.

23. Vairamani, M.; Gross, M. L. G-Quadruplex Formation of ThrombinBinding Aptamer Detected by Electrospray Ionization Mass Spectrometry. J. Am. Chem. Soc. 2003, 125, 42-43.

24. Rueda, M.; Luque, F. J.; Orozco, M. G-Quadruplexes Can Maintain Their Structure in the Gas Phase. J. Am. Chem. Soc. 2006, 128, 3608-3619.

25. Baker, E. S.; Bernstein, S. L.; Bowers, M. T. Structural Characterization of G-Quadruplexes in Deoxyguanosine Clusters Using Ion Mobility Mass Spectrometry. J. Am. Soc. Mass Spectrom. 2005, 16, 989-997.

26. Guo, X.; Bruist, M. F.; Davis, D. L.; Bentzley, C. M. Secondary Structura Characterization of Oligonucleotide Strands Using Electrospray Ionization Mass Spectrometry. Nucleic Acids Res. 2005, 33, 3659-3666.

27. Rosu, F.; Gabelica, V.; Houssier, C.; Colson, P.; Pauw, E. D. Triplex and Quadruplex DNA Structures Studied by Electrospray Mass Spectrometry. Rapid Commun. Mass Spectrom. 2002, 16, 1729-1736.

28. Dapic, V.; Abdomerovic, V.; Marrington, R.; Peberdy, J.; Rodger, A.; Trent, J. O.; Bates, P. J. Biophysical and Biological Properties of Quadruplex Oligodeoxyribonucleotides. Nucleic Acids Res. 2003, 31, 2097-2107.

29. Kypr, J.; Fialova, M.; Chladkova, J.; Tumova, M.; Vorlickova, M. Conserved Guanine-Guanine Stacking in Tetraplex and Duplex DNA. Eur. Biophys. J. Biophys. Lett. 2001, 30, 555-558.

30. Ambrus, A.; Chen, D.; Dai, J.; Bialis, T.; Jones, R. A.; Yang, D. Human Telomeric Sequence Forms a Hybrid-type Intramolecular G-Quadruplex Structure with Mixed Parallel/Antiparallel Strands in Potassium Solution. Nucleic Acids Res. 2006, 34, 2723-2735. 
31. Zhou, J.; Yuan, G. Specific Recognition of Human Telomeric GQuadruplex DNA with Small Molecules and the Conformational Analysis by ESI Mass Spectrometry and Circular Dichroism Spectropolarimetry. Chem. Eur. J. 2007, 13, 5018-5023.

32. Chen, H.; Du, D.M.; Hua, W.T.; He, M.Y.; Xin, B. Study of the Fragmentation Mechanism of Novel Functionalized Macrocycles by Fourier Transform Ion Cyclotron Resonance Mass Spectrometry. J. Mass Spectrom. 2003, 38, 839-844.
33. Wan, K. X.; Shibue, T.; Gross, M. L. Noncovalent Complexes between DNA-binding Drugs and Double-Stranded Oligodeoxynucleotides: A Study by ESI Ion-Trap Mass Spectrometry. J. Am. Chem. Soc. 2000, 122, 300-307.

34. Gabelica, V.; De Pauw, E.; Rosu, F. Interaction Between Antitumor Drugs and a Double-Stranded Oligonucleotide Studied by Electrospray Ionization Mass Spectrometry. J. Mass Spectrom. 1999, 34 1328-1337. 